\title{
Genetic analysis of egg quality traits in White Leghorn chicken
}

\author{
Dasari Sreenivas, Manthani Gnana Prakash, Mallam Mahender and Rudra Nath Chatterjee
}

College of Veterinary Science,

Sri Venkateswara Veterinary University, Rajendranagar, Hyderabad - 500 030, Andhra Pradesh, India

Corresponding author: Sreenivas Dasari, email: dasari117@rediffmail.com

Received: 10-08-2012, Accepted: 15-09-2012, Published online: 12-02-2013

\section{How to cite this article:}

Sreenivas D, Gnana Prakash M, Mahender M and Chatterjee RN (2013) Genetic analysis of egg quality traits in White leghorn chicken, Vet. World 6(5):263-266, doi: 10.5455/vetworld.2013.263-266

\begin{abstract}
Aim: The present study was undertaken to estimate the genetic parameters and to assess the inheritance pattern of egg quality traits in White Leghorns.

Materials and Methods: Data on 480 eggs produced by 40 week old pullets of 4 genetic groups were used for studying egg quality traits. Heritabilities and correlations were estimated by full sib correlation method using Mixed Model Least Squares and Maximum Likelihood (LSMLMW) computer program.

Results: The egg weight, haugh unit, yolk index, albumen index, yolk weight, albumen weight, shell weight and shell thickness ranged from $50.01 \pm 0.48$ to $53.89 \pm 0.43 \mathrm{~g}, 65.38 \pm 0.92$ to $80.98 \pm 1.01,0.341 \pm 0.003$ to $0.353 \pm 0.003,0.056 \pm$ 0.002 to $0.087 \pm 0.002,14.16 \pm 0.13$ to $15.58 \pm 0.12 \mathrm{~g}, 30.92 \pm 0.39$ to $33.18 \pm 0.39 \mathrm{~g}, 4.32 \pm 0.05$ to $5.12 \pm 0.05 \mathrm{~g}$ and $0.336 \pm$ 0.003 to $0.376 \pm 0.003 \mathrm{~mm}$, respectively. Heritability estimates for egg weight, yolk index, albumen index and albumen weight ranged from low to medium while those of haugh unit, yolk weight, shell weight and shell thickness ranged from low to high. The genetic and phenotypic correlations of egg weight with other egg quality traits except shell quality traits were mostly positive and moderate to high. High positive genetic and phenotypic correlations between haugh unit and other traits were observed. Genetic correlation of yolk weight with albumen weight was positive while that with shell quality traits was mostly negative. Shell weight was positively correlated with shell thickness.
\end{abstract}

Conclusion: Significant genetic group differences were observed for various egg quality traits studied. The heritability estimates for different egg quality traits were low to moderate. The association among egg quality traits was positive in general.

Keywords: egg quality traits, heritability, White Leghorn

\section{Introduction}

Poultry farming occupies a pivotal position in bringing about rapid economic growth. In India, during the last five decades, poultry has evolved from subsistence farming to an integrated and highly commercial business oriented enterprise, the development of which was not only in size but also in productivity, sophistication and quality [1]. India is the third largest producer of eggs and fifth largest producer of poultry meat in the world, producing 55.64 billion eggs and about 648,900 tons of poultry meat in 2008 [2]. The overall quality of egg has been considered as the most important trait by the producers and consumers as well for which continuous genetic evaluation of different egg quality traits has become essential in the present market scenario. Therefore, this investigation was taken up to estimate the genetic parameters and to assess the inheritance pattern of various egg quality traits in three strains and control population of White Leghorns.

\section{Materials and Methods}

A total of 480 eggs produced by 40 week old pullets (120 from each of the three pure lines and one control line of White Leghorns) mated to 20 sires were collected and used for studying external and internal egg quality traits. Each sire mated to two dams contributed to 6 progeny at the rate of three progeny per dam.

Eggs were weighed individually to the accuracy of $0.01 \mathrm{~g}$. Thereafter, the eggs were broken and albumen height, haugh unit (HU) etc. were measured using Egg Quality tester (EMT 5200, Japan). Length and width of thick albumen were measured at the longest point by Vernier Callipers with an accuracy of $0.05 \mathrm{~mm}$. Width of the yolk was measured twice at the right angles to each other and averaged. Height of the yolk was measured at the highest part by Ames micrometer with an accuracy of $0.1 \mathrm{~mm}$. Yolk was separated from albumen and weighed nearest to $0.1 \mathrm{~g}$. The shells of broken eggs were dried at room temperature before shell weight was recorded to $0.1 \mathrm{~g}$ accuracy. Shell thickness was measured nearest to 0.01 $\mathrm{mm}$ using a dial thickness gauge at two places on the shell (at broader and at narrower ends) and averaged. Albumen and yolk indices were determined as the ratio of height to width of albumen and yolk as per standard procedures suggested [3,4]. Albumen weight was calculated by subtracting the total weight of the two components (yolk + shell) from the egg weight. 
Table-1. Least squares means for egg quality traits in White Leghorns

\begin{tabular}{|c|c|c|c|c|}
\hline Trait & IWH (Mean) & IWI (Mean) & IWK (Mean) & Control (Mean) \\
\hline$\overline{\text { Egg weight }(\mathrm{g})}$ & $50.01 \pm 0.48^{b}$ & $50.66 \pm 0.47^{b}$ & $53.89 \pm 0.43^{\mathrm{a}}$ & $50.48 \pm 0.42^{b}$ \\
\hline Haugh unit & $72.99 \pm 1.03^{\mathrm{b}}$ & $80.98 \pm 1.01^{\mathrm{a}}$ & $65.38 \pm 0.92^{c}$ & $74.85 \pm 0.92^{b}$ \\
\hline Yolk Index & $0.343 \pm 0.00^{\mathrm{b}}$ & $0.35 \pm 0.00^{\mathrm{a}}$ & $0.341 \pm 0.00^{\mathrm{b}}$ & $0.34 \pm 0.00^{\mathrm{b}}$ \\
\hline Albumen Index & $0.072 \pm 0.00^{\mathrm{b}}$ & $0.09 \pm 0.00^{\mathrm{a}}$ & $0.056 \pm 0.00^{c}$ & $0.08 \pm 0.00^{\mathrm{b}}$ \\
\hline Yolk weight(g) & $14.16 \pm 0.13^{c}$ & $14.70 \pm 0.13^{\mathrm{b}}$ & $15.58 \pm 0.12^{\mathrm{a}}$ & $14.84 \pm 0.12^{b}$ \\
\hline Percent Yolk weight & $28.28 \pm 0.24^{b}$ & $29.17 \pm 0.23^{\mathrm{a}}$ & $29.15 \pm 0.25^{\mathrm{a}}$ & $29.56 \pm 0.24^{a}$ \\
\hline Albumen Weight (g) & $31.53 \pm 0.43^{\mathrm{b}}$ & $31.19 \pm 0.43^{b}$ & $33.18 \pm 0.39^{\mathrm{a}}$ & $30.92 \pm 0.39^{\mathrm{b}}$ \\
\hline Percent albumen weight & $62.96 \pm 0.30^{\mathrm{a}}$ & $61.31 \pm 0.31^{\mathrm{b}}$ & $61.24 \pm 0.30^{\mathrm{b}}$ & $61.10 \pm 0.28^{\mathrm{b}}$ \\
\hline Shell weight(g) & $4.32 \pm 0.05^{c}$ & $4.77 \pm 0.05^{\mathrm{b}}$ & $5.12 \pm 0.05^{\mathrm{a}}$ & $4.72 \pm 0.05^{\mathrm{b}}$ \\
\hline Percent Shell weight & $8.76 \pm 0.09^{\circ}$ & $9.53 \pm 0.08^{\mathrm{ab}}$ & $9.61 \pm 0.10^{\mathrm{a}}$ & $9.34 \pm 0.09^{b}$ \\
\hline Shell Thickness (mm) & $0.336 \pm 0.00^{c}$ & $0.376 \pm 0.00^{\mathrm{a}}$ & $0.362 \pm 0.00^{b}$ & $0.365 \pm 0.00^{b}$ \\
\hline
\end{tabular}

Means with different superscripts in each row differ significantly

Table-2. Heritability and correlation coefficients for egg quality traits in different strains of White Leghorns

\begin{tabular}{|c|c|c|c|c|c|c|c|c|}
\hline & EW & $\mathrm{HU}$ & YI & Al & YW & AW & sw & ST \\
\hline \multicolumn{9}{|l|}{ IWH Strain } \\
\hline $\mathrm{EW}$ & $0.226 \pm 0.028$ & $-0.181 \pm 0.156$ & $0.803 \pm 0.270$ & $0.234 \pm 0.110$ & $-0.670 \pm 0.153$ & $0.814 \pm 0.285$ & $-0.744 \pm 0.148$ & $0.345 \pm 0.183$ \\
\hline HU & -0.203 & $0.272 \pm 0.174$ & $0.471 \pm 0.121$ & $0.912 \pm 0.316$ & $0.670 \pm 0.153$ & $-0.835 \pm 0.348$ & $-0.744 \pm 0.148$ & $-0.778 \pm 0.263$ \\
\hline $\mathrm{YI}$ & -0.135 & 0.195 & $0.107 \pm 0.074$ & $0.816 \pm 0.135$ & $0.612 \pm 0.162$ & $0.587 \pm 0.112$ & \# & $-0.143 \pm 0.109$ \\
\hline $\mathrm{Al}$ & -0.154 & 0.914 & 0.205 & $0.121 \pm 0.062$ & $0.831 \pm 0.297$ & $-0.529 \pm 0.233$ & $0.335 \pm 0.240$ & \# \\
\hline YW & 0.768 & -0.302 & -0.203 & -0.278 & $0.322 \pm 0.371$ & $0.448 \pm 0.128$ & $-0.816 \pm 0.132$ & \# \\
\hline AW & 0.964 & -0.135 & -0.079 & -0.077 & 0.581 & $0.214 \pm 0.222$ & $0.694 \pm 0.498$ & $-0.624 \pm 0.124$ \\
\hline sw & 0.531 & -0.187 & -0.211 & -0.209 & 0.528 & 0.388 & $0.186 \pm 0.080$ & $0.354 \pm 0.128$ \\
\hline ST & -0.229 & -0.008 & -0.097 & $\begin{array}{l}-0.062 \\
-\end{array}$ & -0.035 & -0.301 & 0.128 & $0.419 \pm 0.193$ \\
\hline \multicolumn{9}{|l|}{ IWI Strain } \\
\hline $\mathrm{EW}$ & $0.180 \pm 0.122$ & $0.411 \pm 0.248$ & $0.919 \pm 0.547$ & $0.329 \pm 0.124$ & $0.592 \pm 0.231$ & $0.741 \pm 0.126$ & $0.481 \pm 0.216$ & $-0.263 \pm 0.178$ \\
\hline $\mathrm{HU}$ & 0.549 & $0.322 \pm 0.224$ & $0.585 \pm 0.202$ & $0.909 \pm 0.301$ & $0.341 \pm 0.131$ & $0.874 \pm 0.126$ & $0.741 \pm 0.123$ & $0.681 \pm 0.220$ \\
\hline $\mathrm{YI}$ & 0.068 & 0.009 & $0.211 \pm 0.113$ & $0.785 \pm 0.108$ & $0.709 \pm 0.301$ & $0.417 \pm 0.118$ & $0.176 \pm 0.102$ & $0.244 \pm 0.116$ \\
\hline $\mathrm{Al}$ & 0.406 & 0.883 & 0.011 & $0.146 \pm 0.027$ & $0.754 \pm 0.289$ & $0.429 \pm 0.101$ & $-0.836 \pm 0.689$ & $0.176 \pm 0.102$ \\
\hline YW & 0.611 & 0.485 & 0.012 & 0.239 & $0.245 \pm 0.209$ & $0.254 \pm 0.109$ & $-0.969 \pm 0.942$ & $-0.136 \pm 0.020$ \\
\hline AW & 0.892 & 0.398 & 0.073 & 0.346 & 0.238 & $0.218 \pm 0.236$ & $0.237 \pm 0.151$ & $-0.258 \pm 0.321$ \\
\hline SW & 0.294 & 0.280 & 0.023 & 0.203 & 0.346 & -0.034 & $0.161 \pm 0.079$ & $0.336 \pm 0.162$ \\
\hline ST & 0.580 & 0.501 & 0.037 & 0.326 & 0.648 & 0.312 & 0.501 & $0.351 \pm 0.193$ \\
\hline \multicolumn{9}{|l|}{ IWK Strain } \\
\hline $\mathrm{EW}$ & $0.255 \pm 0.067$ & $0.330 \pm 0.138$ & $-0.456 \pm 0.155$ & $0.437 \pm 0.386$ & $0.591 \pm 0.079$ & $0.998 \pm 0.001$ & $-0.477 \pm 0.180$ & $0.313 \pm 0.259$ \\
\hline HU & -0.005 & $0.299 \pm 0.250$ & $0.290 \pm 0.073$ & $0.375 \pm 0.096$ & $0.437 \pm 0.386$ & $0.998 \pm 0.001$ & & $0.818 \pm 0.152$ \\
\hline YI & -0.064 & 0.027 & $\#$ & $0.711 \pm 0.088$ & $0.752 \pm 0.124$ & $0.512 \pm 0.314$ & \# & $\#$ \\
\hline $\mathrm{Al}$ & -0.155 & 0.726 & 0.447 & $\#$ & $-0.045 \pm 0.123$ & $-0.404 \pm 0.027$ & \# & $-0.474 \pm 0.463$ \\
\hline YW & 0.023 & 0.195 & 0.077 & 0.165 & $0.277 \pm 0.101$ & $0.013 \pm 0.598$ & $-0.324 \pm 0.127$ & $-0.667 \pm 0.412$ \\
\hline AW & 0.965 & -0.045 & -0.074 & -0.184 & -0.225 & $0.124 \pm 0.036$ & $0.038 \pm 0.102$ & $-0.334 \pm 0.118$ \\
\hline sW & 0.054 & -0.004 & -0.050 & -0.019 & 0.403 & -0.128 & $0.202 \pm 0.177$ & $0.318 \pm 0.122$ \\
\hline ST & 0.111 & 0.031 & -0.183 & -0.052 & 0.016 & 0.053 & 0.542 & $0.270 \pm 0.129$ \\
\hline \multicolumn{9}{|c|}{ Control Strain } \\
\hline EW & $0.293 \pm 0.022$ & $0.298 \pm 0.170$ & $0.660 \pm 0.418$ & $0.394 \pm 0.191$ & $0.339 \pm 0.131$ & $0.856 \pm 0.101$ & $0.556 \pm 0.101$ & $-0.718 \pm 0.128$ \\
\hline HU & 0.132 & $0.217 \pm 0.177$ & $0.298 \pm 0.101$ & $0.450 \pm 0.214$ & $0.339 \pm 0.182$ & $0.839 \pm 0.111$ & $0.801 \pm 0.447$ & $0.616 \pm 0.124$ \\
\hline YI & 0.154 & 0.486 & $0.237 \pm 0.186$ & $0.821 \pm 0.134$ & $0.650 \pm 0.210$ & $0.539 \pm 0.106$ & $0.239 \pm 0.107$ & $0.201 \pm 0.142$ \\
\hline $\mathrm{Al}$ & 0.031 & 0.842 & 0.521 & $0.171 \pm 0.136$ & $0.241 \pm 0.132$ & $-0.285 \pm 0.265$ & $0.512 \pm 0.125$ & $0.218 \pm 0.110$ \\
\hline YW & 0.578 & -0.279 & -0.074 & -0.307 & $0.192 \pm 0.136$ & $0.131 \pm 0.102$ & $0.828 \pm 0.119$ & \# \\
\hline AW & 0.953 & 0.279 & 0.219 & 0.164 & $0.323-0.100$ & $0.219 \pm 0.202$ & $0.147 \pm 0.134$ & $0.245 \pm 0.108$ \\
\hline sW & 0.546 & -0.161 & -0.036 & -0.159 & 0.001 & 0.418 & \# & $0.352 \pm 0.223$ \\
\hline ST & 0.137 & -0.032 & -0.018 & -0.054 & 0.096 & 0.116 & 0.137 & $0.304 \pm 0.301$ \\
\hline
\end{tabular}

Heritability estimates are on diagonals; Genetic correlations are in above diagonals and phenotypic correlations are in below diagonals

Heritabilities and correlations were estimated by full sib correlation method using Mixed Model Least Squares and Maximum Likelihood (LSMLMW) computer program [5].

\section{Results and Discussion}

Phenotypic means: Significant differences $(P \leq 0.01)$ were observed among the three strains and control population with respect to various egg quality traits (Table-1). The IWK strain had significantly higher egg weight $(53.89 \pm 0.43 \mathrm{~g})$ when measured from other two strains and control population. The three strains in the present study were obtained from different sources and with different selection criteria. Similar differences were reported by earlier authors in White Leghorns [6-11]. Egg weight ranged from $50.01 \pm 0.48$ to $53.89 \pm$ $0.43 \mathrm{~g}$, which is in agreement with the published reports [8,11-13]. Haugh unit, a measure of albumen quality was in the range of $65.38 \pm 0.92$ in IWK to $80.98 \pm 1.01$ in IWI strain, which is in accordance with the published reports [6,8-11]. Higher haugh unit values than those observed in the present study were also reported in different breeds [14-16].

Yolk index and albumen index were highest in IWI strain $(0.353 \pm 0.003$ and $0.087 \pm 0.002$, respectively) and lowest in IWK strain $(0.341 \pm 0.003$ and 0.056 \pm 0.002 , respectively). There were reports of higher yolk index value (17) and higher albumen index value (11) and very lower albumen index values [7, 8 and 10] in comparison to the present findings. The weights of yolk, albumen and shell and their percent weights over the egg weight were measured and analyzed for comparison. The IWK strain had higher yolk, albumen and shell weights as expected on the ground that it had higher egg weight, while percent weights varied in the trend. Similar observations $[10,15]$ were reported in White Leghorns, while higher percent shell weights [12,18-20] were observed in native / backyard poultry. This suggests that the shells of White Leghorns contribute lesser proportion to the egg weight when compared to native / backyard poultry. In the present study, the shell thickness ranged from $0.336 \pm 0.003$ in IWH to $0.376 \pm 0.003 \mathrm{~mm}$ in IWI strain, which is comparable to many reports in literature $[7,8,10,14]$. 
The reports of higher shell thickness values $[13,15,16$, 21] in backyard / other poultry could be due to their higher percentage contribution to egg weight.

Heritability Estimates: Egg weight was found to be moderately heritable as the heritability ranged from $0.180 \pm 0.122$ to $0.293 \pm 0.022$, similar to the earlier reports $[6,7,10]$ in White Leghorns. The heritability estimate of haugh unit ranged from $0.217 \pm 0.177$ to $0.322 \pm 0.224$ across the populations studied, which is in agreement with the observations of different earlier authors $[7,8,10,11]$. The heritability estimates of albumen and yolk indices in some populations could not be obtained probably because of small population size. Yolk index and albumen index were found to be low to moderately heritable. Reviewed literature had varied results ranging from 0.01 [17] to 0.70 [7]. The heritability estimate of yolk weight and albumen weight were in the range of 0.097 to 0.721 and 0.124 to 0.250 , respectively. Available literature on these estimates is very scanty except one report of similar heritability estimates for these traits [10]. The heritability estimates of shell weight and shell thickness were found to be low to highly heritable which ranged from 0.161 to 0.419 across different strains, indicating that selection could be applied for the improvement of shell quality. These findings corroborate with the previous reports $[7,10,17]$.

Correlations: The genetic and phenotypic correlations of egg weight with egg quality traits were mostly positive and moderate to high in magnitude while they varied with shell quality parameters. Similar positive correlations of egg weight with other egg quality traits in White Leghorns were reported [17,23]. As haugh unit is a measure of albumen height corrected for egg weight, the high genetic ( 0.375 to 0.912$)$ and phenotypic correlations ( 0.726 to 0.914$)$ with albumen index are not surprising. The correlations of haugh unit with other traits were also positive and moderate to high in magnitude. These findings are in agreement with the report of very high (0.895) genetic correlation with albumen index and varied correlations with other traits [23]. The genetic correlations of Yolk index with albumen index, yolk weight and albumen weight were high and positive while the same varied with shell weight and shell thickness.

The phenotypic correlations varied both in direction and magnitude in comparison with similar observations in IWD strain [23]. Albumen index had mostly positive genetic correlations with yolk weight, shell weight and shell thickness. The phenotypic correlations with other traits varied while the environmental correlations were mostly positive as comparable to earlier reports $[17,23]$. The genetic correlation of yolk weight with albumen weight was positive in all strains while that with shell weight and shell thickness was negative. Phenotypic correlation with albumen weight, shell weight and shell thickness was positive. In contrast, highly negative correlations between percent yolk weight and percent albumen weight were also reported [23]. The genetic correlation of albumen weight with shell weight was positive in all strains while it was negative with shell thickness except in control population. The phenotypic correlation between these traits was varied. Shell weight was positively correlated with shell thickness in all the populations at genetic, phenotypic and environmental levels. This indicates that genetic or environmental factors affecting shell weight would bring about simultaneous change in shell thickness, since both of them constitute the shell strength. High positive genetic and phenotypic correlations (0.792 and 0.610 , respectively) between shell percent and shell thickness were also reported [23].

\section{Conclusion}

Significant genetic group differences were observed for various egg quality traits studied. The heritability estimates for different egg quality traits were low to moderate. The association among egg quality traits was positive in general. Further studies are required in finding out the association of external and internal egg quality parameters so as to take appropriate breeding plans for producing customer friendly quality eggs.

\section{Authors' contribution}

SD, GPM and RC designed and implemented the study. SD, GPM recorded and analysed the data. SD drafted the manuscript. SD, GPM, MM and RC revised the manuscript. All authors read and approved the final manuscript.

\section{Acknowledgements}

The first author is thankful to the Sri Venkateswara Veterinary University for permitting the study and to the officials and staff of the Project Directorate on Poultry, Hyderabad for providing facilities during the study.

\section{Competing interests}

Authors declare that they have no competing interest.

\section{References}

1. Rajkumar, U., Sharma, R.P., Bhattacharya, T.K., Niranjan, M., Rajaravindra, K.S., Reddy, B.L.N. and Chatterjee, R.N. (2010) Inheritance of egg quality traits in broiler Naked Neck and dwarf chicken. Indian Journal of Poultry Science 45: 1-5.

2. Food and Agricultural Organization (2010) Core production data. http://faostat.fao.org/site/340/default.aspx, Retrieved on 22-07-2012.

3. Heimen, V. and Carver, J. S. (1936) The albumen index as a physical measurement of observed egg quality. Poultry Science 15: 141-148.

4. Funk, E. M. (1948) The relation of yolk index determined in natural position to the yolk index as determined after separating the yolk from albumen. Poultry Science 27: 376380 .

5. Harvey, W. R. (1990) User's guide. LSMLMW and MIXMDL PC-2 version. Mixed model least-squares and maximum likelihood computer programme. Ohio, U.S.A.

6. Chatterjee, R. N., Sharma, R. P., Niranjan, M., Reddy, B. L. 
N. and Mishra, A. (2006) Genetic studies on egg quality traits in different White Leghorn populations. Indian Journal of Animal Genetics and Breeding 27: 51-54.

7. Devi, K. S. and Reddy, P. M. (2004) Effect of strain on physical egg quality characteristics in White Leghorn layers. Indian Journal of Poultry Science 39: 190-192.

8. Devi, K. S. and Reddy, P. M. (2005) Genetic studies on certain economic traits in White Leghorn and cross-bred chicken. Indian Journal of Poultry Science 40: 56-58.

9. Giriraj, K., Narayanankutty, K. and Veeramani, P. (2008) Evaluation of reciprocal White Leghorn strain crosses for egg quality traits in deep litter system. Indian Journal of Poultry Science 43: 241-242.

10. Jayalaxmi, P., Prasad, V. L. K., Sree Rama Murthy, A. and Eswara Reddy, C. (2001) Inheritance of various egg quality traits in three strains of White Leghorns. Indian Vet. J.,78: 820-823.

11. Singh, B., Kumar, S., Kaur, N. and Yadav, S. N. (2009) Evaluation of external and internal egg quality traits of hill fowl reared under backyard system. Indian Journal of Poultry Science 44: 25-29.

12. Chatterjee, R. N., Rai, R. B., Kundu, A., Senani, S. and Sunder, J. (2007) Egg quality traits of indigenous breeds of chicken of Andaman. Indian Veterinary Journal 84: 206208.

13. Chen, C.F., Lee, Y.P., Lee, Z.H., Huang, S.Y. and Huang, H.H. (1993) Heritabilities and genetic correlations of egg quality traits in Taiwan's local chicken. Asian Journal of Animal Science 6: 433-440.

14. Momoh, O.M., Ani, A.O. and Ugwuowo, L.C. (2010) Partperiod egg production and egg quality characteristics of two ecotypes of Nigerian local chickens and their $F_{1}$ crosses. International Journal of Poultry Science 9: 744-748.

15. Padhi, M. K., Rai, R. B., Senani, S. and Saha, S. K. (1998)
Assessment of egg quality in different breeds of chicken. Indian Journal of Poultry Science 33: 113-115.

16. Rajkumar, U., Sharma, R.P., Niranjan, M., Rajaravindra, K.S., Reddy, B.L.N., Bhattacharya, T.K. and Chatterjee, R.N. (2009) Effect of genotype and age on egg quality traits in Naked Neck chicken under tropical climate from India. International Journal of Poultry Science 8: 1151-1155.

17. Sharma, P. K., Varma, S. K., Sharma, R. K. and Brijesh Singh. (2002) Genetic parameters of production and egg quality characters in White Leghorn. Indian Journal of Poultry Science 37:181-182.

18. Singh, B., Singh, H., Singh, C. V. and Brijesh Singh. (2000) Genetic parameters of growth, egg production and egg quality traits in White Leghorn. Indian Journal of Poultry Science 35: 13-16.

19. Wolc, A., White, I.M.S., Hill, W.G. and Olori, V.E. (2010) Inheritance of hatchability in broiler chickens and its relationship to egg quality traits. Poultry Science 89: 23342340.

20. Yadav, S. N., Kumar, Y., Singh, B., Ghosh, A. K. and Kaur, N. (2009) Evaluation of egg quality traits of chickens reared under backyard system in western Uttar Pradesh. Indian Journal of Poultry Science 44: 261-262.

21. Zita, L., Tumova, E. And Stolc, L. (2009) Effects of genotype, age and their interaction on egg quality in brownegg laying hens. Actavet. brono 78: 85-91.

22. Yakabu, A., Ogah, D.M. and Barde, R.E. (2008) Productivity and egg quality characteristics of free range naked neck and normal feathered Nigerian indigenous chickens. International Journal of Poultry Science 7: 579-585.

23. Jayalaxmi, P., Prasad, V. L. K., Sree Rama Murthy, A. and Eswara Reddy, C. (2002) Correlations among various egg quality traits in White Leghorn. Indian Vet. J., 79: 810-813.

$* * * * * * * *$ 